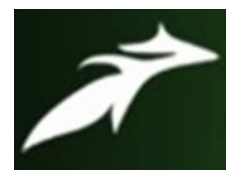

Amita et al, International Journal of Advances in Agricultural Science and Technology,

Vol.7 Issue.10, October-2020, pg. 1-5

ISSN: 2348-1358

Impact Factor: 6.057

NAAS Rating: 3.77

\title{
PROTECTED CULTIVATION IN INDIA: MEETING CHALLENGES
}

\author{
Amita; Vijay Bahadur \\ Email Id:- amitachoudhary027@gmail.com
}

\begin{abstract}
The future of protected cultivation in India is very vast but highly depending upon the technicality and recommendation of the technology has to play a significant role under varied agro climatic conditions as a means for sustainable crop intensification, vertical growth of productivity, leading to optimization of water and fertilizer use efficiency in an environment of water scarcity in addition to better control of product quality and safety, in line with the market demands ,standards and regulations .In the near future, first and most important requirement for the use of protected cultivation technology is for its large-scale use for raising healthy planting material for all horticultural crops and secondly to use the technology for hybrid seed production of vegetables rather production of fresh food for better economic viability in the country and mostly in cluster approach. Further, for sustainability of the technology, it is utmost important to develop a huge skilled manpower in the form of youths in two sets, one set for designing, fabrication/installation and maintenance of protected structure and the other for crop production and management under protected conditions.
\end{abstract}

\section{INTRODUCTION}

With time it has been proved that protected cultivation is a better technology to enhance land productivity and quality of the produce by providing a logical and technical solution to manage the major biotic and abiotic stresses encountered under open field cultivation of horticultural crops especially to vegetables. The effectiveness of the technology has been observed world over. In the last decade, area under protected cultivation in various parts of the world has increased exponentially in countries like China for adoption of various protected cultivation technology in different forms like mulching , use of temporary plastic walls in open field, low tunnel, walk-in- tunnel, insects proof, net houses, shade net houses, green houses etc. Presently china is the world leader in cultivating horticultural crops under different protected condition and the estimated area under protected cultivation has reached around 3.5 million ha. And out of the area nearly $96 \%$ is only being used for cultivation of vegetables and for their hybrids seeds production.

\section{PROTECTED CULTIVATION IN INDIA}

India being a country with diverse climatic region has shown an overall growth of around 50,000 ha area under protected cultivation in the last two decades. The success rate of these technology varied significantly depending upon the climatic condition. In north India this technology faced high challenges for making them successful against the harsh climatic condition. Whereas, in the mild climatic area like that of Bengaluru and Pune the success rate has been high. Basically the growth of this technology in the country happened mainly due to government policies providing handsome subsidies under the schemes launched under NHM, NHB, RKVY etc. but merely by the technical beauty of the technology. The technical know-how for adoption of protected cultivation technology under Indian condition was not to the level at the time of inception, with time research and development work carried out by various public sector institutions in collaboration with developed countries gradually reflected that for various Indian climatic condition that technical design of different protected structure need modification suitable to the region specific needs.

But protected cultivation technology requires carefull planning, attention and details about timing of production and moreover, harvest time to coincide with high market prices, choice of varieties adopted to the off season 


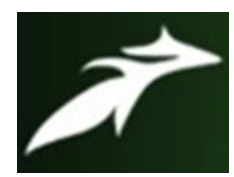

Amita et al, International Journal of Advances in Agricultural Science and Technology,

Vol.7 Issue.10, October-2020, pg. 1-5

ISSN: 2348-1358

Impact Factor: 6.057

NAAS Rating: 3.77

environments and able to produce economical yields of high quality produce etc. Even though the application of chemical foe controlling biotic stresses is also low under protected structures which gives a high quality safe vegetables for human consumption. By using protected structure, it is also possible to raise off- season and long duration vegetables crops of high quality. Vegetable and cut flower farming in agri-entrepreneurial models targeting various niche markets of the big cities is inviting regular attention of vegetables and flowers growers for diversification from traditional ways of crop cultivation to the modern methods like protected cultivation.

\section{Challenges In Protected Cultivation in India}

-Lack of trained professional and skilled man power for designing, fabrication of protected structure thereafter, maintenance of the structure and for protected cultivation of various high value crops.

-Non -availability of region specific design of protected structure for varied agro climatic condition.

-Lack of practical training institutions and advisory services in the area of protected cultivation.

- Fabrication of protected structure has come up as a big business, taking an opportunity small industries are sacrificing with the quality of material to be used to gain more profit and also lack of understanding of quality of basic steel and cladding material used for fabrication of structure.

-Lack of availability of crop varitires and planting material specific to protected cultivation specifically with public sector institutions, its management practices etc as the available planting material/seeds with private sector companies to costly.

-Lack of demand driven cultivation without proper marketing strategy creates problem for proper disposal of the quality produce and farmers cannot get low premium price, therefore cluster approach for taking up protected cultivation as a whole is required.

-Increasing threat of soil borne fungus like Fusarium and root knot nematodes for protected cultivation of vegetables.

\section{Potential and Strategies}

Protected cultivation technology has tremendous potential over and across the country under varied agro climatic condition. The most potential areas where high scale interventions are required to be promoted are:

-Use of plug tray nursery technology on commercial scale for raising horticultural crops can come up as a big business.

-Large -scale use of insect proof net houses for vegetable production and also for seed production of hybrids.

- Large scale use of naturally ventilated green houses under harsh condition of arid and semi arid regions.

-Large scale use of insect proof net houses and naturally ventilated green house for hybrid seed production in vegetables for increasing the overall profitability of farmers.

-Large scale use plastics mulches for commercial vegetable cultivation under open fields and also under green houses and even under net houses.

- Large scale use of micro grafted technology for developing resistance plants material against soil borne problems.

-Lrage scale cultivation of fruit crops like Papaya and pomegranate under insect proof net houses. 


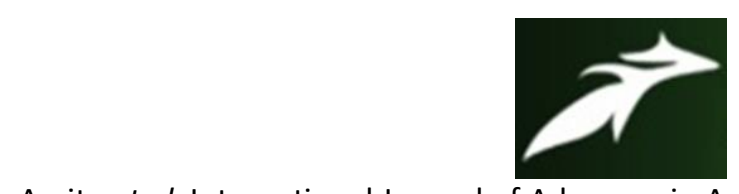

Amita et al, International Journal of Advances in Agricultural Science and Technology,

Vol.7 Issue.10, October-2020, pg. 1-5

ISSN: 2348-1358

Impact Factor: 6.057

NAAS Rating: 3.77

-Large scale application of low pressure drip irrigation system for managing and an area of 1000-2000 $\mathrm{m}^{2}$ area.

- Open roof type high tunnels can be used commercially in northern parts of the country and even inder temperate condition it can be rewarding.

-Large scale application of GAP procedure and standards for protected cultivation of crops like vegetables will help to catch international trades.

-Government support most be extended for self fabrication mode of temporary low cost structure like insect proof net houses, shade net houses, walk-in tunnels of vegetables and flowers.

-Large scale production and distribution of healthy vegetables and flowers seedling to the large section of grower on nominal price.

-Government should support and promote protected cultivation in cluster approach especially in peri-urban areas of the countries.

-Government should promote to developed input hubs for protected cultivation in multi-locations in PPP mode.

-All the protected cultivation cluster must be mandatorily clubbed with rain water harvesting infra-structure and facilities.

-To establish convergence and synergy among various on-going and planned govt. programme in the field of protected cultivation development.

-To ensure edequate, appropriate, time bound and concurrent attention to all links introduction under protected condition, post production on farm value addition processing and consumption chain.

-Use of solar energy for running drip system and up to some extent for running heating and cooling devices of the protected structure.

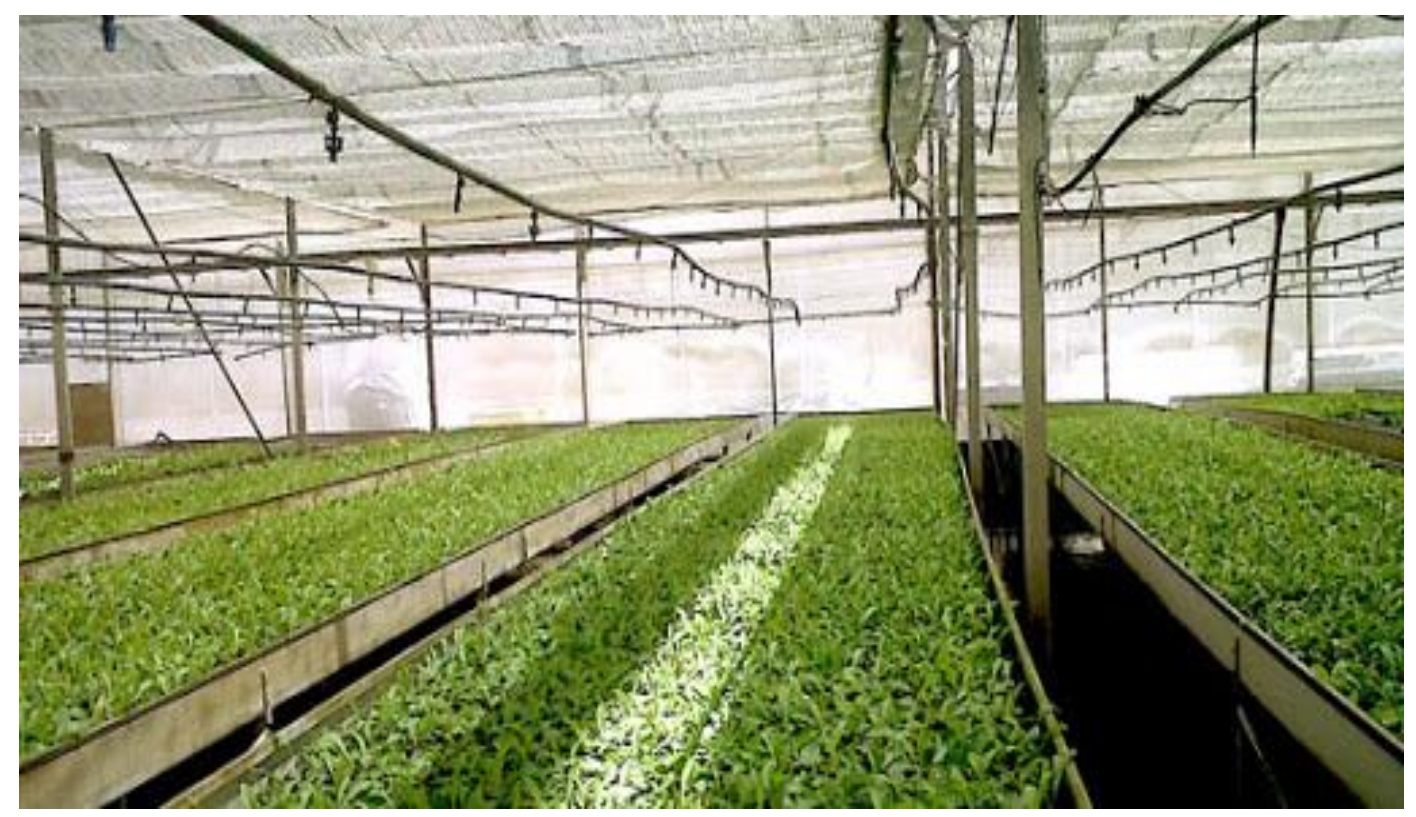




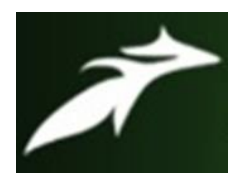

Amita et al, International Journal of Advances in Agricultural Science and Technology, Vol.7 Issue.10, October-2020, pg. 1-5

ISSN: 2348-1358

Impact Factor: 6.057 NAAS Rating: 3.77

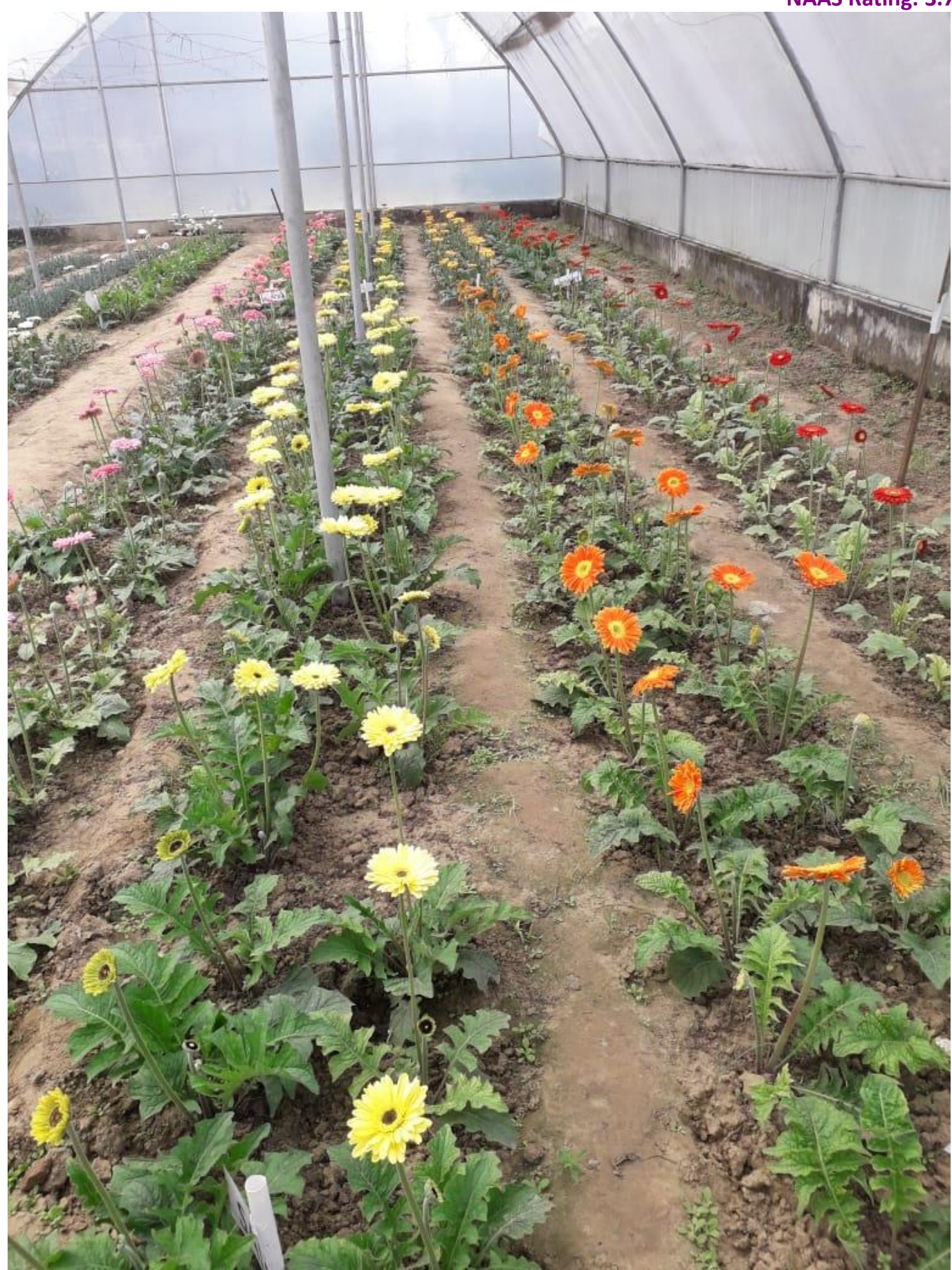




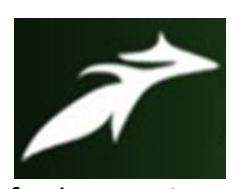

Amita et al, International Journal of Advances in Agricultural Science and Technology, Vol.7 Issue.10, October-2020, pg. 1-5

ISSN: 2348-1358

Impact Factor: 6.057

NAAS Rating: 3.77
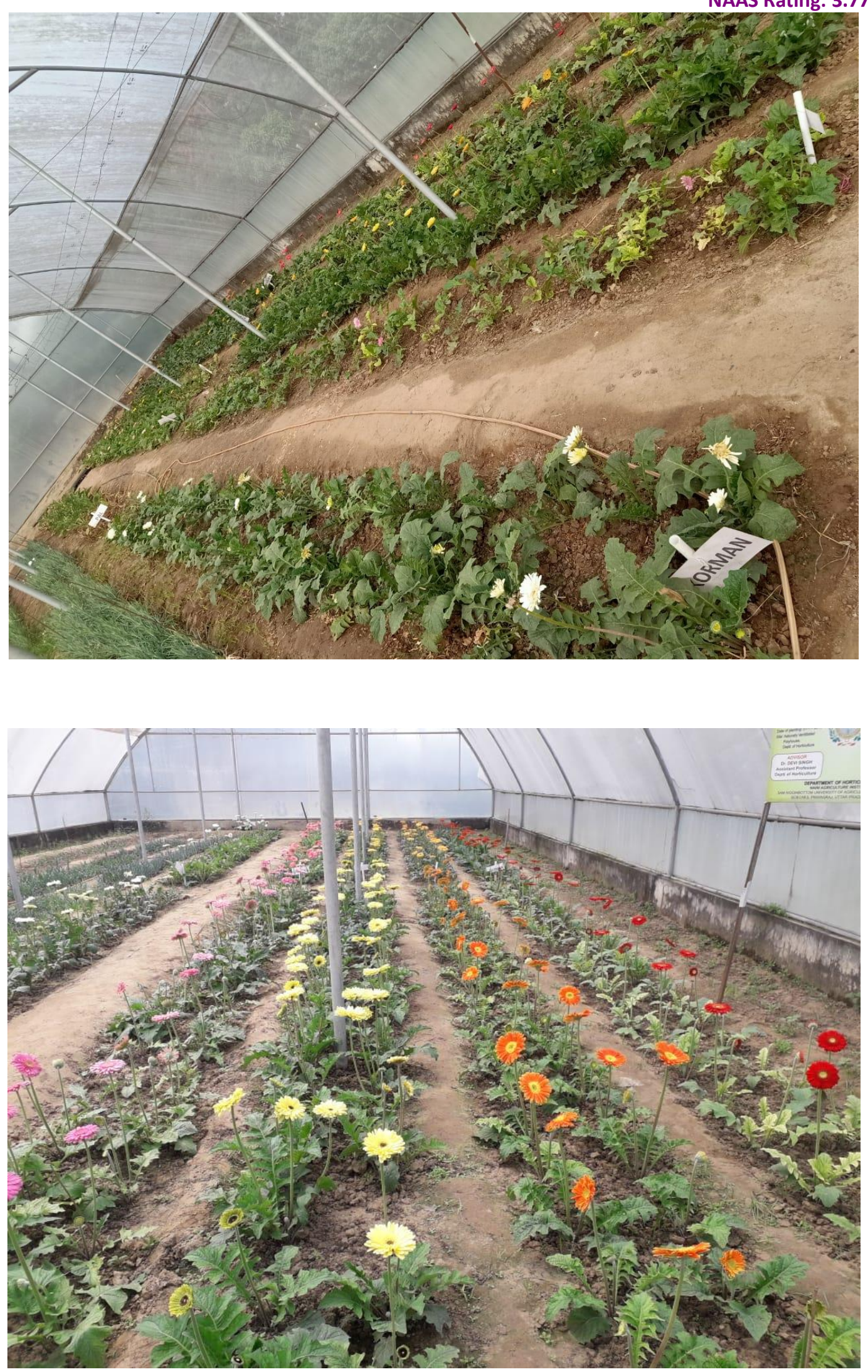